\title{
Extended VEOT Framework - Implemented in a Smart Boutique
}

\author{
S. Pothumani, Ashok Kumar Anandam, Nikita sharma, S.Franklin
}

\begin{abstract}
With advent of new technologies in communication and security in IoT and advantages of Cloud computing, have multiplied, the opportunities in Smart homes, Offices and Equipments. Augmented Reality (AR) adds another dimension to the experience. The proposed system makes use of all these concepts including Edge computing to design a Smart Boutique. A boutique is a unique store that sells stylish, luxury and fashion clothing, jewelry, or other exquisite goods. Considering the richness to be experienced by the Customers, the usage of these techniques would amply complement their senses. VEoT or Virtual Environment of Things is a framework for combining all these technologies to mix both real world objects and Virtual Reality. It is very important to cater to the needs of customer in a unique way, giving personal touch to the business. This would create repeat orders and would attract more customer footfalls. The base paper gives a concrete architecture for combining IoT and $A R$ with the help of Edge server. We have tried to make the system robust, including a kiosk touch screen to enable the customer to have more information on Boutique and its articles. The goal of the system is to produce renewed customer experience and create a Smart Boutique with technology.
\end{abstract}

Index Terms-Augmented Reality, Internet of Things (IoT), Kiosk, Virtual Environment of Things (VEoT), Cloud Server.

\section{INTRODUCTION}

he environment we are used to is made up of natural things, which are real and can be felt by senses. We are in the age, where real things can be enhanced to give a visual feeling, which otherwise cannot be seen by the eyes. This virtualization in real thingshas opened new environment for human beings to visualize everything in a different perspective. We call Virtual Environment of Things, in which the virtual environment interacts with real things by using the latest technologies of augmented reality and Internet of Things (IoT). The IoT devices make different real objects to act according to the instructions and AR enhances the object to give more details on it. A framework has been built on this and the VEoT or Virtual Environment of Things

Revised Manuscript Received on July 22, 2019

S. Pothumani, Department of CSE, Bharath Institute of Higher Education and Research, Chennai, Tamilnadu, India.

Ashok Kumar Anandam, Department of CSE, Bharath Institute of Higher Education and Research, Chennai, Tamilnadu, India.

Nikita sharma, Student,Department of CSE, Bharath Institute of Higher Education and Research, Chennai, Tamilnadu, India

S.Franklin, Student,Department of CSE, Bharath Institute of Higher Education and Research, Chennai, Tamilnadu, India framework came into existence. [26],[28],[30]

This framework has the ability to connect by internet, all the physical devices. These devices can interact with each other and act based on it. The devices not only identifies itself, but creates manifestations of itself, Its connection with surrounding objects and database data, makes it more useful,in many applications. Many IoT objects and myriad of applications, act in unison to create, what is called "ambient intelligence".

World has become a Global village transmitting intelligent information from one part to the other part of the world. Various devices like computers, tablets and Smartphone enable these things to happen..Now IoT has opened another new avenue where anything can pass information to another thing intelligently. With advent of IoT, more value is added to the information system. [13], [15] ,[17]

When reality is enhanced or extrapolated to give a visual cue about its abilities or so called avatars, which are its manifestations, it is defined asaugmented reality. When it is completely artificial environment, it is the Virtual reality. Using an existing environment and overlaying new information on top of it, is the main functionality of augmented reality.

In 1990, Boeing researcher Thomas Caudell coined the term augmented reality, for the usage of the head-mounted displays by electricians, when assembling complicated wiring harnesses. After 1998, when the yellow "first down" line that began appearing in televised football games, the augmented reality brought new dimensions to watching games in television. Today, there are many AR products like Google glass, Smart glasses, HoloLens and heads-up displays in car windshields, which represent the advances in AR technology.Certainly this technology has made huge impact in many industries. [20], [22], [24]

Augmented reality apps are graphics system where the real world images are overlaid with its manifestations. An animated overlay or any details of the object is associated with an augmented reality "marker" in the real world.Some of the AR applications typically include global positioning system (GPS) to track the user's location. More complex AR programs are used for 
object recognition, machine vision and gesture recognition technologies. [25],[27],[29]

Edge computing is processing of data near the edge of your network, instead of processing in a centralized data warehouse. In effect, the processing is accomplished near the data generated.

Edge computing is an open architecture that features the enabling of mobile computing and Internet of Things (IoT) technologies with decentralized processing power. In edge computing, data is not transmitted to a remote data center, but eventually processed by the device itself.

Edge computing processes real-time data without any latency and also enables data-stream acceleration. It is very instantaneous in allowing the smart applications and devices to respond to given data, as its being created, eliminating lag time. This is an important feature of Edge computing which can be used for technologies such as self-driving cars, and has all important benefits for other businesses as well.

Edge computing can process large amounts of data near the device, in an efficient way. This reduces the usage of internet bandwidth, which can provide lot of leverage for processing other data as well. This ensures that the cost is reduced and the applications can run in a remote location efficiently. Additionally, the data is not processed in a public cloud, an added security layer for sensitive data.

Now we have seen three components namely IoT, AR and Edge computing. By using all these technologies, we can produce remarkable experience for the customer in a boutique and so-called "Virtual Environment of Things (VEoT)" comes into play. VEoT is a framework to provide a seamless interaction of real world smart objects and virtual world objects in a computer generated virtual environment. This can improve the Customer relationship with the boutique. The proposed system also integrates a kiosk into the mix, which can help the customers of large boutique to virtually do the shopping in the premises, instead of moving to all parts of the boutiquee. [19],[21],[23]

\section{PROPOSED METHOD - EXTENDED VEOT FRAMEWORK}

\section{A. VEoT Framework}

VEoT can be understood as a paradigm for depicting virtualization on real-world things, where these entities can request and respond with virtual objects in a real-time manner. The demonstration presents an extended VEoT platform focusing on the scalability and security of IoT devices in collaboration with an AR device to create a more complex and secure 4D user experience.

Backbone of VEoT is REX or Resource exchange, which has three components namely Resource Manager an embodiment of all the RESTful API compliant web services,
Smart Thing Manager which encapsulates all the smart things in virtual devices and Event Manager to handle external environment event triggers and states of the devices. This is the NVE or Networked Virtual environment, since it integrates real world objects and virtual objects to give an unique experience which has been a main aspect in a Smart boutique in marketing and attracting prospective customers.

\section{B. Extended by integration of AR, IoT and Kiosk}

VEoT framework is extended by using another device Kiosk. This gives additional capability to the framework for more customer friendly features. The kiosk can provide more general information about the boutique as well provide a trouble shooting feature of $\mathrm{AR}$ and IoT devices. With increase in various IoT devices and their capabilities, the framework needs a robust system. And this is provided by controlling IoT devices from Cloud server. The edge server complements the cloud server in giving quick response to commands from Cloud server. IoT devices can communicate between them by using M2M features. Lightweight encryption algorithm is used for security of IoT devices.

\section{Components of Extended VEoT framework}

There are three main components in this extended framework. They are AR device, IoT Device and Kiosk. AR devices can be of any type like Heads upDisplays (HUD), Holographic displays, smart glasses or Handheld/Smartphone based. In this project, we have considered Smart glasses. In video see through glasses, the user views the reality captured by one or more cameras and the computer generated imagery is overlaid on the combined view.IoT devices or any of the physical things in the internet of things can compute and connect to a network both wired and wireless. IoT devices can be a simple sensor to a more complicated wireless system. The ability to communicate with servers and among themselves has been harnessed in this project.An interactive kiosk is consists of a computer screen featuring specialized hardware and software that provides access to the relevant information. This is a useful addition to the VEoT framework, making modern shops smarter. The cloud server and edge server helps in managing and controlling these components[32],[34],[36]

\section{Features of Extended VEoT framework}

The various drawbacks in VEoT framework has been taken care of in extended VEoT. Some of the drawbacks in VEoT framework are Scalability, Communication between the IoT Devices, Security concerns and ability to cater to complicated implementations. So the main features of the extended VEoT framework are[38],[40],[42]

(i) Improved Scalability - The scalability has been improved by placing the smart gateway in Cloud server. This will allow more number of IoT devices connected to the system and controlled.

(ii) Large Scaled implementations - $\quad$ The extended framework can now 
be used for large scaled implementations because of its robustness in handling more number of devices.

(iii) M2M communication - Now the IoT devices can send data to each other and based on the status, various activities can be implemented.

(iv) Security feature - To solve security concerns, the extended VEoT implements IoT authentication and IoT encryption.

Overall, the framework has been improved from existing structure to solve various disadvantages found in the existing framework.

\section{E. Choice of implementing in a boutique}

We have implemented this framework in a boutique shop. The choice of a boutique was based on the scope that can be applied to the system. Since the framework has various components like IoT device, AR device and Kiosk, we thought a boutique will need these ingredients to make it smarter and efficient. Since a boutique is considered to be a luxury goods shop, displaying the items in an unique way, would add more richness to the boutique. The customer would also get a feel of the richness provided the boutique and that could be an important selling point.

\section{F. Architecture}

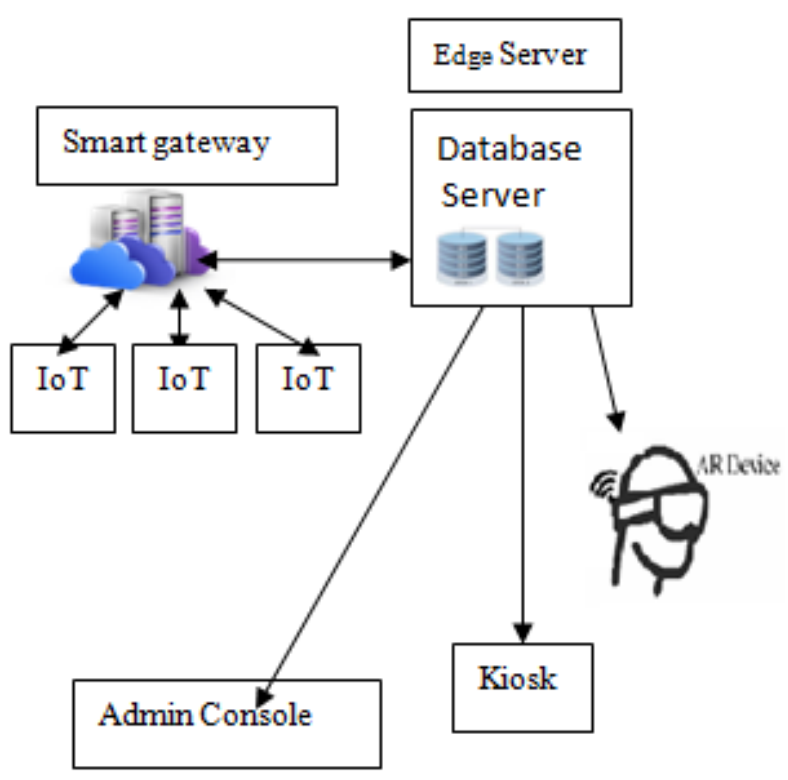

Fig. 1. Architecture of Extended VEoT Framework

The Smart gateway has been placed in a cloud server, so any RESTful commands for the IoT is sent from this gateway. The AR device sends instruction to the IoT device for the chosen item through the Smart gateway. The IoT device activated and executes the instructions requested by the gateway. The Kiosk is a separate entity, which can be used in conjunction with IoT or AR device. The database server provides the data storage and retrieval for these devices. The admin console controls the initiation of all the devices and servers. The edge server has been considered in the architecture to provide quick response to IoT devices.

\section{IMPLEMENTATION}

We implemented the extended VEoT framework in a smart Boutique which is exclusively selling garments and ornaments. Both hand-made and machine-made items are being displayed. Initially categorized the items based on a theme in different rack. Each rack is fitted with the IoT device which could do a simple on-off switch to any other complicated activities like changing colors of the garments. IoT devices are connected to the cloud server, which controls the IoT devices. The AR devices are given to the registered customers of the boutique. They can wear it and see through the objects in the rack. The AR device shows information about all the items in the rack. The user can choose further information in $\mathrm{AR}$ device. The various $\mathrm{AR}$ images are projected for the item chosen. The IoT devices communicate with each other and provide information to the customer. Then the customer returns the AR device and he can mark items interested and examine it physically. The kiosk can also be used by the customer for getting information about the items sold by the boutique. This would give an unique experience to the customer.

\section{RESULT ANALYSIS}

Simulated environment has been created to demonstrate this project. Software has been created to simulate it. AR Devices and IoT devices have to be setup initially. Then the various items are set up with their details and assigned to an IoT device. Multiple items can be assigned to an IoT device. When a customer enters the boutique, the salesman registers the customer entry and assigns the AR device, which he wants to wear. Once the customer activates the AR simulator, the list of items is displayed on the screen. He can choose the required item and get their details displayed on the AR simulator. Once the item is selected, the corresponding IoT device activates on the IoT simulator. And Kiosk simulator can display the item marked for prospective buying.

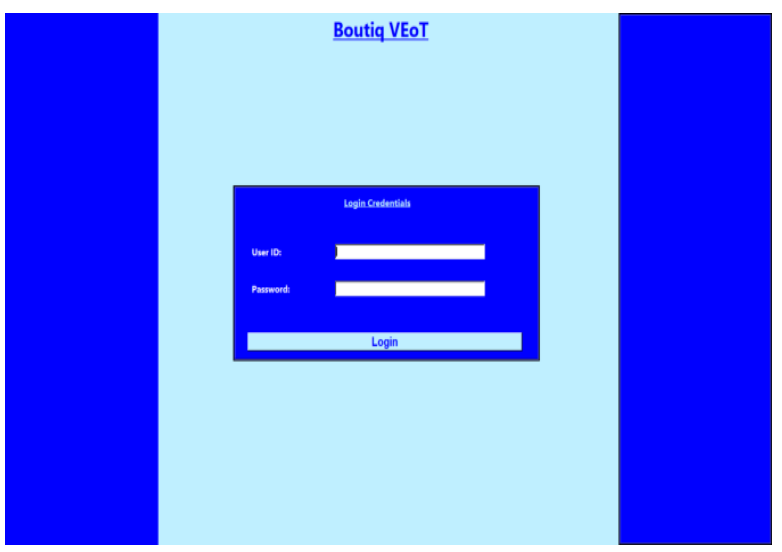

Fig. 2. Login screen Blue Eyes Intelligence Engineering \& Sciences Publication 

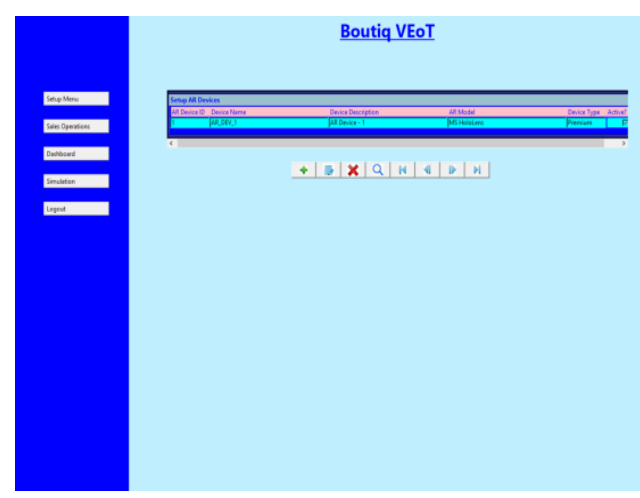

Fig. 3. Setup AR Device
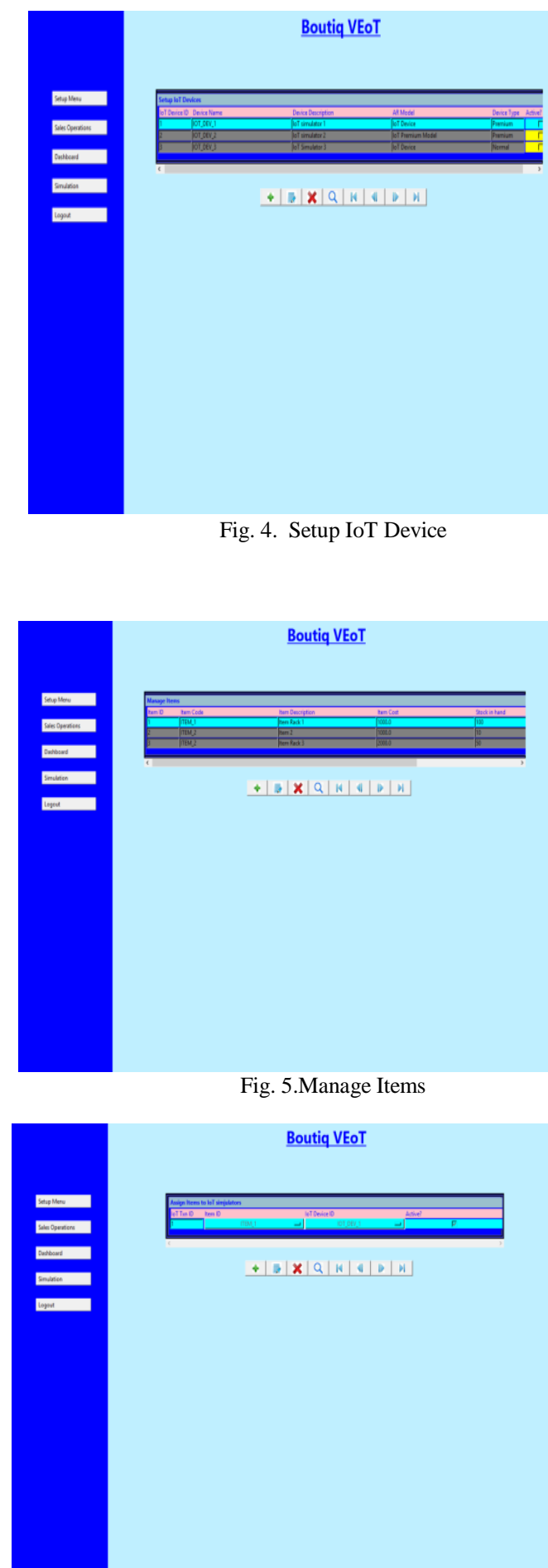

$+|\operatorname{sen}| \alpha|d| \nabla|n|$

$+|=| \times|k| a|p| n \mid$

Fig. 4. Setup IoT Device

$+|\operatorname{x}| a|w|+|D| n \mid$

Fig. 5.Manage Items

Boutiq VEOT

$+|B| x|a| w|\&| \nabla|n|$
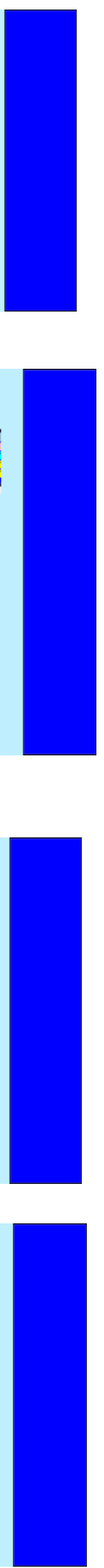

Fig. 6. Assign IoT Devices

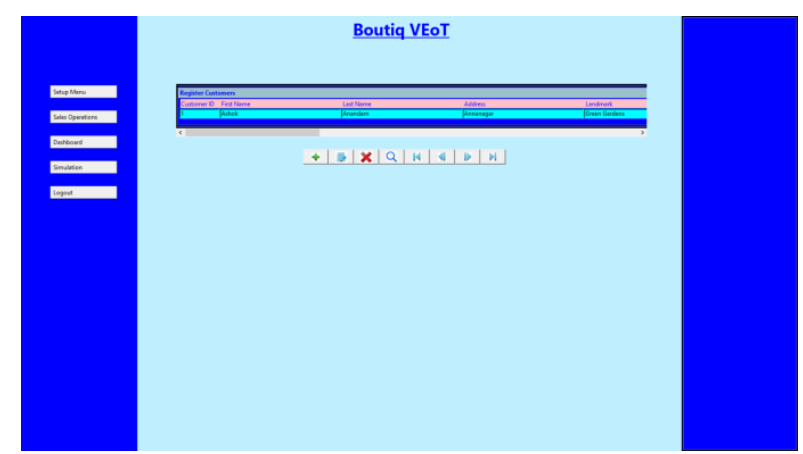

Fig. 7. Register Customer

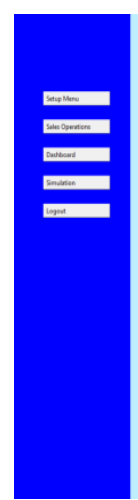

Boutiq VEoT

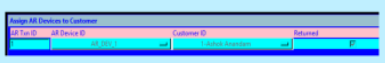

$+|=| x|a| r|\cdot| D|n|$

Fig. 8. Assign AR Device

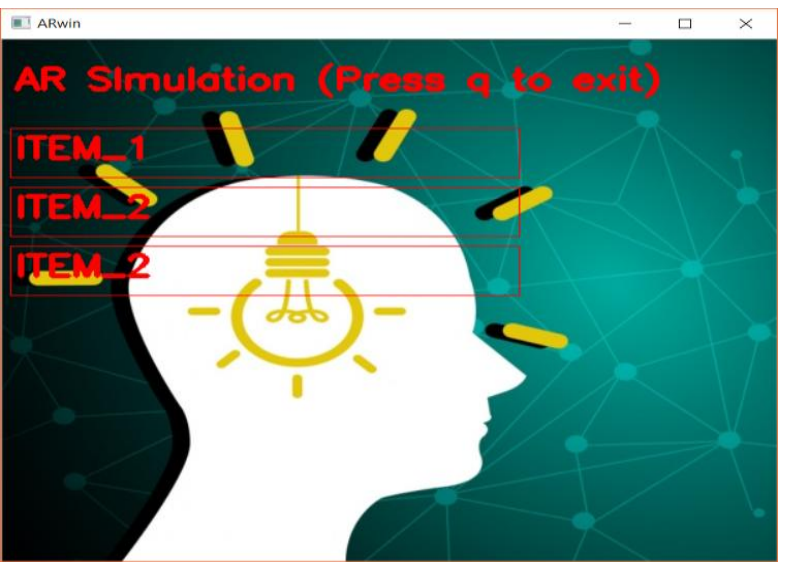

Fig. 9. AR Simulation with Items list

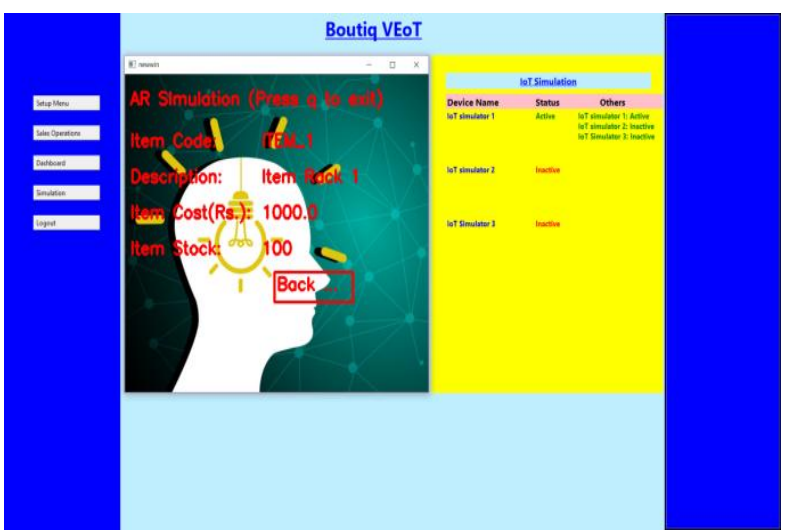

Fig. 10. AR Simulation with Item details 


\section{CONCLUSION}

The system proposes an efficient mix of various devices applying the framework of VEoT, for building a customer friendly Smart Boutique. There are three different kinds of devices: IoT device, AR device and a kiosk touch screen, in this system. To make more secure IoT device, we have used a lightweight encryption method for data protection from these devices. The Smart gateway which connects to the Iot Devices is placed in a Cloud server, to make it scalable, so that more number of devices can be connected to it and controlled. IoT devices are made to communicate between each other using Machine to Machine communication. All the database and communications between various devices are managed by an Edge server. The scalability and security features can be enhanced in future enhancements to the framework. And can also be applied to large scale implementations with latest technologies.

\section{REFERENCES}

[1] Kumaravel A., Rangarajan K.,Algorithm for automaton specification for exploring dynamic labyrinths,Indian Journal of Science and Technology,V-6,I-SUPPL5,PP-4554-4559,Y-2013

[2] P. Kavitha, S. Prabakaran "A Novel Hybrid Segmentation Method with Particle Swarm Optimization and Fuzzy C-Mean Based On Partitioning the Image for Detecting Lung Cancer" International Journal of Engineering and Advanced Technology (IJEAT) ISSN 2249-8958, Volume-8 Issue-5, June 2019

[3] Kumaravel A., Meetei O.N.,An application of non-uniform cellular automata for efficient cryptography,2013 IEEE Conference on Information and Communication Technologies, ICT 2013,V-,I-,PP-1200-1205,Y-2013

[4] Kumarave A., Rangarajan K.,Routing alogrithm over semi-regular tessellations,2013 IEEE Conference on Information and Communication Technologies, ICT 2013,V-,I-,PP-1180-1184,Y-2013

[5] P. Kavitha, S. Prabakaran "Designing a Feature Vector for Statistical Texture Analysis of Brain Tumor" International Journal of Engineering and Advanced Technology (IJEAT) ISSN: 2249-8958, Volume-8 Issue-5, June 2019

[6] Dutta P., Kumaravel A.,A novel approach to trust based identification of leaders in social networks,Indian Journal of Science and Technology,V-9,I-10,PP--,Y-2016

[7] Kumaravel A., Dutta P.,Application of Pca for context selection for collaborative filtering,Middle - East Journal of Scientific Research,V-20,I-1,PP-88-93,Y-2014

[8] Kumaravel A., Rangarajan K.,Constructing an automaton for exploring dynamic labyrinths,2012 International Conference on Radar, Communication and Computing, ICRCC 2012,V-,I-,PP-161-165,Y-2012

[9] P. Kavitha, S. Prabakaran "Adaptive Bilateral Filter for Multi-Resolution in Brain Tumor Recognition" International Journal of Innovative Technology and Exploring Engineering (IJTTEE) ISSN 2278-3075, Volume-8 Issue-8 June, 2019

[10] Kumaravel A.,Comparison of two multi-classification approaches for detecting network attacks, World Applied Sciences Journal,V-27,I-11,PP-1461-1465,Y-2013

[11] Tariq J., Kumaravel A.,Construction of cellular automata over hexagonal and triangular tessellations for path planning of multi-robots, 2016 IEEE International Conference on Computational Intelligence and Computing Research, ICCIC 2016,V-,I-,PP--,Y-2017

[12] Sudha M., Kumaravel A.,Analysis and measurement of wave guides using poisson method,Indonesian Journal of Electrical Engineering and Computer Science, V-8,I-2,PP-546-548,Y-2017

[13] Ayyappan G., Nalini C., Kumaravel A.,Various approaches of knowledge transfer in academic social network,International Journal of Engineering and Technology,V-,I-,PP-2791-2794,Y-2017

[14] Kaliyamurthie, K.P., Sivaraman, K., Ramesh, S. Imposing patient data privacy in wireless medical sensor networks through homomorphic cryptosystems 2016, Journal of Chemical and Pharmaceutical Sciences 92.

[15] Kaliyamurthie, K.P., Balasubramanian, P.C. An approach to multi secure to historical malformed documents using integer ripple transfiguration 2016 Journal of Chemical and Pharmaceutical Sciences 92

[16] A.Sangeetha,C.Nalini,"Semantic Ranking based on keywords extractions in the web", International Journal of Engineering \& Technology, 7 (2.6) (2018) 290-292

[17] S.V.GayathiriDevi,C.Nalini,N.Kumar,"An efficient software verification using multi-layered software verification tool "International Journal of Engineering \& Technology, 7(2.21)2018 $454-457$

[18] C.Nalini,ShwtambariKharabe,"A Comparative Study On Different Techniques Used For Finger - Vein Authentication", International Journal Of Pure And Applied Mathematics, Volume 116 No. 8 2017, 327-333, Issn: 1314-3395

[19] M.S. Vivekanandan and Dr. C. Rajabhushanam, "Enabling Privacy Protection and Content Assurance in Geo-Social Networks", International Journal of Innovative Research in Management, Engineering and Technology, Vol 3, Issue 4, pp. 49-55, April 2018.

[20] Dr. C. Rajabhushanam, V. Karthik, and G. Vivek, "Elasticity in Cloud Computing", International Journal of Innovative Research in Management, Engineering and Technology, Vol 3, Issue 4, pp. 104-111, April 2018.

[21] K. Rangaswamy and Dr. C. Rajabhushanamc, "CCN-Based Congestion Control Mechanism In Dynamic Networks", International Journal of Innovative Research in Management, Engineering and Technology, Vol 3, Issue 4, pp. 117-119, April 2018.

[22] Kavitha, R., Nedunchelian, R., "Domain-specific Search engine optimization using healthcare ontology and a neural network backpropagation approach", 2017, Research Journal of Biotechnology, Special Issue 2:157-166

[23] Kavitha, G., Kavitha, R., "An analysis to improve throughput of high-power hubs in mobile ad hoc network" , 2016, Journal of Chemical and Pharmaceutical Sciences, Vol-9, Issue-2: 361-363

[24] Kavitha, G., Kavitha, R., "Dipping interference to supplement throughput in MANET" , 2016, Journal of Chemical and Pharmaceutical Sciences, Vol-9, Issue-2: 357-360

[25] Michael, G., Chandrasekar, A.,"Leader election based malicious detection and response system in MANET using mechanism design approach", Journal of Chemical and Pharmaceutical Sciences(JCPS) Volume 9 Issue 2, April - June 2016

[26] Michael, G., Chandrasekar, A.,"Modeling of detection of camouflaging worm using epidemic dynamic model and power spectral density", Journal of Chemical and Pharmaceutical Sciences(JCPS) Volume 9 Issue 2, April - June 2016.

[27] Pothumani, S., Sriram, M., Sridhar, J., Arul Selvan, G., Secure mobile agents communication on intranet,Journal of Chemical and Pharmaceutical Sciences, volume 9, Issue 3, Pg No S32-S35, 2016

[28] Pothumani, S., Sriram, M., Sridhar , Various schemes for database encryption-a survey, Journal of Chemical and Pharmaceutical Sciences, volume 9, Issue 3, Pg NoS103-S106, 2016

[29] Pothumani, S., Sriram, M., Sridhar, A novel economic framework for cloud and grid computing, Journal of Chemical and Pharmaceutical Sciences, volume 9, Issue 3, Pg No S29-S31, 2016

[30] Priya, N., Sridhar, J., Sriram, M. "Ecommerce Transaction Security Challenges and Prevention Methods- New Approach" 2016 ,Journal of Chemical and Pharmaceutical Sciences, JCPS Volume 9 Issue 3.page no:S66-S68

[31] Priya, N.,Sridhar,J.,Sriram, M."Vehicular cloud computing security issues and solutions" Journal of Chemical and Pharmaceutical Sciences(JCPS) Volume 9 Issue 2, April - June 2016

[32] Priya, N., Sridhar, J., Sriram, M. "Mobile large data storage security in cloud computing environment-a new approach" JCPS Volume 9 Issue 2. April - June 2016

[33] Anuradha.C, Khanna.V, "Improving network performance and security in WSN using decentralized hypothesis testing "Journal of Chemical and Pharmaceutical Sciences(JCPS) Volume 9 Issue 2, April - June 2016

[34] Anuradha.C, Khanna.V, "A novel gsm based control for e-devices" Journal of Chemical and Pharmaceutical Sciences(JCPS) Volume 9 Issue 2, April - June 2016

[35] Anuradha.C, Khanna.V, "Secured privacy preserving sharing and data integration in mobile web environments " Journal of Chemical and Pharmaceutical 
Sciences(JCPS) Volume 9 Issue 2, April - June 2016.

[36] Sundarraj, B., Kaliyamurthie, K.P. Social network analysis for decisive the ultimate classification from the ensemble to boost accuracy rates 2016 International Journal of Pharmacy and Technology 8

[37] Sundarraj, B., Kaliyamurthie, K.P. A content-based spam filtering approach victimisation artificial neural networks 2016 International Journal of Pharmacy and Technology 83 .

[38] Sundarraj, B., Kaliyamurthie, K.P. Remote sensing imaging for satellite image segmentation 2016 International Journal of Pharmacy and Technology $\quad 8 \quad 3$.

[39] Sivaraman, K., Senthil, M. Intuitive driver proxy control using artificial intelligence 2016 International Journal of Pharmacy and Technology 84 .

[40] Sivaraman, K., Kaliyamurthie, K.P. Cloud computing in mobile technology 2016 Journal of Chemical and Pharmaceutical Sciences 92.

[41] Sivaraman, K., Khanna, V. Implementation of an extension for browser to detect vulnerable elements on web pages and avoid click jacking 2016 Journal of Chemical and Pharmaceutical Sciences 92

\section{AUTHORS PROFILE}

S.Pothumani, Assistant Professor, Department of Computer Science \& Engineering, Bharath Institute of Higher Education and Research, Chennai, India

Ashok Kumar Anandam, PG Student, Department of Computer Science \& Engineering, Bharath Institute of Higher Education and Research, Chennai, India

Nikita sharma, Student, Department of Computer Science \& Engineering, Bharath Institute of Higher Education and Research, Chennai, India

S.Franklin, Student, Department of Computer Science \& Engineering, Bharath Institute of Higher Education and Research, Chennai, India 